\title{
Surfies versus Westies: Kinship, Mateship and Sexuality in the Cronulla Riot
}

\author{
Anthony Redmond \\ Centre for Aboriginal Economic Policy Research, \\ Australian National University
}

\begin{abstract}
In the predominantly affluent and Anglo Sutherland Shire in southern suburban Sydney, neighbourhood and extended kinship ties continue to exert powerful forces shaping local identities. During the riot of 11 December 2005 these identities were brought into relief by being pitted against the Lebanese immigrant youth who have been spatially and morally separated from Anglo-Australians. I argue that the strong homosociality exhibited in several different contexts by young Anglo-Australian men (the barbecue area, a sports team's 'gang bang', the violent defence of a neighbourhood controlled beach) and young Lebanese Australian men (paternal cousin and fraternal solidarities, an infamous series of gang rapes, their response to the White riot at Cronulla) are forms of separation that produce particular kinds of male sexual, class and ethnic subjects. I propose that a study of the role of kinship and cohort relationships in Anglo-Australian and Lebanese-Australian male groups should include the nature of incestophobia as an essential component of the precipitating fantasies leading to the riot and the subsequent retaliation.
\end{abstract}

To possess the capital of authority necessary to impose a definition of a situation (where collective judgment falters) is to be able to mobilize the group by solemnizing, officializing, universalizing a private incident (for example, presenting an insult to a particular woman as an insult to the whole group). (Bourdieu 1977: 40)

This remark by Pierre Bourdieu seems to capture something essential to the group dynamics operating at Cronulla Beach in southern suburban Sydney on the weekend of 11-12 December, 2005. During these events, a number of people 'of middle-eastern appearance' were set upon and beaten by members of a large crowd, consisting mostly of young Anglo-Australians who had congregated in the area in response to rumour, SMS messages and radio broadcasts decrying the behaviour of Lebanese-Australian youths on Cronulla beach. One of the sources of the wounded rage of the young Anglo-Australians who rioted on that day was the verbal insults ('sluts' and 'whores') thrown at AngloAustralian women on Cronulla beach by young Lebanese-Australian men. The other cited cause of the riot was an assault on off-duty Anglo-Australian lifesavers. This incident was repeatedly portrayed in media coverage as a premeditated attack on a pair of these lifesavers, suggesting that they had been targeted in the distinctive red and yellow bathing costumes and caps, which have made them instantly recognisable icons of White

THE AUSTRALIAN JOURNAL OF ANTHROPOLOGY, 2007, 18:3, 336-350 
Australia. ${ }^{1}$ Far from being part of the same 'brotherhood of the sea', these 'clubbies' have commonly been perceived by 'surfies' (whose sub-cultural identity hinges strongly on an ethic of non-conformism) as their dorky opposite numbers with whom verbal and physical feuds have long been waged. The assaults on this lifesaver and the sexual insults made to 'Aussie' girls on the beach, though, seems to have brought these two usually opposed Anglo-Australian factions together as one; between ourselves, you are my enemy, but in regard to young Lebanese-Australian men, you are my friend - in short, 'structural relativity' (Evans-Pritchard 1940). In the build up to the riot and in the subsequent public rationalisations of them, the sexual insults and the assault were construed as provocations to the entire cohort of young Anglo-Australians, some of whom evidently felt that their collective Anglo masculine pride, the honour of 'their' women, and the subculture of sun, surf and sex were under attack from the 'Wogs' descending upon the predominantly Anglo beach districts from the more inland, southwestern suburbs of Sydney, which have large immigrant populations.

The actions and self-representations of the Anglo-Australian and Lebanese-Australian youths in this exchange of insults suggests that understanding how localised kin and cohort groups are constituted is crucial to an analysis of the Cronulla 'White riot' as well as to the subsequent retaliation on the following day when a car-convoy of young Lebanese-Australian men arrived in the suburb, smashing residents' cars and physically intimidating and assaulting Anglo passers-by.

\section{The local context}

Sutherland Shire, of which Cronulla Beach is 'the jewel in the crown', is one of the most exclusively Anglo areas of Sydney. Approximately 80 per cent of its population was born in Australia, the next most common countries of origin being the United Kingdom, New Zealand and South Africa. The percentage of residents claiming 'Australian ancestry' (a fairly ambiguous label but one in which Anglo-Australian descent is assumed) is the highest in the Sydney metropolitan area. 'The Shire' (a self-applied label instantly evoking images of rural Britishness) has a high socio-economic status (Healy and Birrell 2003), yields a high conservative vote, and constitutes Sydney's second-largest 'BibleBelt', rivalled in this regard only by the north-western suburbs of Sydney where Charismatic Christian churches such as Hillsong are based. Alhtough young people from the south-western suburbs have a legendary devotion to their cars, the so-called 'Wog invasion' of which the residents of the Shire complained was mostly facilitated by the public transport system. As one of the few southern beaches located on the train line from the south-western suburbs, Cronulla beach is accessible to those who are of too independent an age to be kept within their home neighbourhoods but who are too young to drive. The significance of the rail link to Cronulla was, of course, well known to the rioters who quickly targeted the railway station.

Cronulla appears to have been renowned as a predominantly Anglo-Australian enclave for several generations, so that Mediterranean migrant groups have tended to make greater use of Coogee and Maroubra beaches which are situated north of Cronulla but closer to the Kurnell Peninsula where Sydney's transport/industrial precincts are located and where their workforces have traditionally resided (Abraham 2005).

The strong form of 'clan solidarity' displayed by Anglo-Aussies ('Skip/Skippy' or 'Convict' as they are sometimes derogatorily known by non-Anglos) during these events was constituted in relation to a parallel Lebanese-Australian collectivity, ${ }^{2}$ by tapping into the pervasive fear and hatred of the Arab world (or 'Islamophobia' (Hage 1998, 2003)) reproduced in this and other Western countries since the first Gulf War of 1990, and 
rising to a crescendo during the recent years of the 'war on terror'. As the previous citation from Bourdieu suggests, Anglo-clan solidarity at Cronulla was achieved through 'solemnizing and universalizing' the sexual insults made by Lebanese-Australian men against Anglo-Aussie women. The highly localised response quickly spilled over into a national furore invested with the renewed macro-scale solidarity in the White Englishspeaking world (particularly between the nation-states of Australia, the USA, Canada and Britain) constituted vis à vis the Arabic speaking world under the rubric of 'the coalition of the willing'. On 11 December 2005, this oppositional solidarity was displayed at Cronulla by young men displaying portable barbecues and 'Eskies' (plastic beer coolers) while wrapped in Australian flags and invoking 'the spirit of Gallipoli' via text messages urging Anglo-Aussies to 'fight the Turk on the beaches' and to 'support Leb and Wogbashing day'.

As Bruce Kapferer (1988) noted, an Anglo-Australian nationalist solemnity is constituted partly in opposition to an informal male camaraderie embodying principles of 'egalitarian individualism', an interpersonal quality often generated around the paradigmatically outdoor spaces of the barbecue area and the beach. For all its apparent egalitarianism, though, the barbecue area is also a subtly competitive social space (as Kapferer's double-barrelled term suggests) that, while cementing bonds of mateship over food and drink, also elicits a less overt individuating violence within and between groups of 'mates'. This dynamic is neatly captured by the Anglo-Australian colloquialism, 'men, meat and metal', which describes a fantasy of sacrificial male homosociality produced around the barbecue. The phrase evokes not so much men's shared commensality (eating or drinking together) as the sharing of an outdoor cooking and drinking space with the male host who cooks meat for the gathering. I make this distinction because the mensa around which these men will later gather to eat is usually shared with their female kin, who traditionally provide the vegetable foods accompanying the meat. The cultural ideal of pitting together 'men, meat and metal' suggests a conscious recognition that such scenes elicit men's aggressive devouring of each other. Although this aggression is mostly projected onto the meat and the various pieces of metal equipment (knives, tongs, scrapers and an iron-plate cooking surface), it also commonly involves men engaging in semi-jocular 'ribbing' (another carnivorous trope) of each other which may erupt into fights or arguments as the alcohol begins to take effect.

One of the paradigmatic features of an Anglo-Australian barbecue is the marked gender separations which supposedly allow both women and men to banter freely on sexual, marital and other matters without fear of embarrassment or censure by their opposite-sex kin. This gender separation is widely valued by both men and women as important to the retention of personal autonomy. While men have traditionally gathered around the outdoor fire/barbecue plate as their visual and social focus, women at such events are often found tending children and/or preparing salads or mixing drinks in a separate space. Those who cross the barbecue area's implicit spatial/gender boundaries are often regarded with some suspicion by members of their own gender group and may be the recipient of their exclusionary responses or of flirting from the opposite sex group since the border-crosser has thereby indicated an at least partially deregulated sexuality.

Before and after the Cronulla riot, the young Anglo-Australian participants themselves widely acknowledged that it was the insults made against their female kin across a gender/ethnicity divide which precipitated their collectivising rage. Some amongst the young Anglo-Australian crowd, emboldened by more or less explicit support from their older ethnic and class counterparts in the media over the previous week, ${ }^{3}$ were able to 'impose a definition of the situation', as Bourdieu puts it, on the vacillating crowd, at least temporarily. 


\section{Licking the wounds of the 2002 Bali bombings}

That same solemnising and universalising dynamic had been evident three year's earlier in the surfie subculture's response to the 2002 Bali bombings in which another iconic place of sun, surf and sex was experienced as being violently penetrated by a threatening presence. ${ }^{4}$ For well over a quarter of a century, Bali has been a major site of pilgrimage for young Australian travellers and has come to constitute part of their imagined backyard of fun. The visual splendour of Bali's natural and cultural landscape, especially its Hindu festivities and religious iconography, had long appealed to the hippy-surfie aesthetic with which Australian travelers pioneered tourism to the island in the $1970 \mathrm{~s}$, following the trail blazed by a number of Australian artists in the 1940s and 1950s. Against this background aesthetic a more heavily commercialised tourist culture in which dance-party drugs and binge-consumption of alcohol are commonplace has emerged in the last two decades or so. This change has a strong class component. Although Bali was once the destination of the 'counter-culture' children of the middle-class, it has now become very much a working-class family holiday destination.

Because of Bali's unique characteristics, Australian tourists, prior to the 2002 bombings, had generally remained oblivious to the fact that the island paradise is encompassed within the predominantly Muslim Indonesian nation. That ethical objections and/or hateful envy could be produced in Bali by a conspicuous and affluent Western hedonism had been easily ignored. Members of the Anglo-Aussie surf subculture shared the shock and awe experienced by Australians more generally after the 2002 bombings. This sense of shock was augmented by the now infamous Schapelle Corby 'marijuana-in-the boogie-board' case and the later arrest of an Australian lingerie model for possession of the drug ecstasy outside a Bali nightclub (for further background see MacRae 2006). Underlying the popular outrage in Australia at these arrests was a sense that fun-loving young Australians on holiday were suddenly and inexplicably being targeted and punished for using recreational drugs in the same manner that they had done for decades without hindrance or prosecution. Until the 2002 bombings and these drugrelated arrests took place, the changing political dynamics between Australia and Indonesia following Australia's military interventions in Iraq and East Timor had been deemed fairly irrelevant to the average Aussie tourist. This sense that Bali, like Cronulla, had become 'a paradise lost' (see also A. Lattas 2007) as a result of the bombings evoked a strong image of the bombers as usurping, angry puritans whose actions had no sense of proportion. This paralleled the common sentiment that the sentences meted out by the Indonesian judiciary to the Aussie tourists caught with drugs were also lacking in any sense of proportion.

Mourning ceremonies on Australian beaches for the Australian victims of the Bali bombing displayed a wistful and insular response to the widely perceived threat to some fundamental aspects of national and sub-cultural identity, a response that closely mimicked the sense of wounded narcissism, which swept across the USA following the terror attacks of September 11, 2001. These mourning ceremonies included Australian surfers paddling out on their boards with flowers between their teeth, and forming a circle in the water. While purportedly drawing upon 'traditional Polynesian mourning ceremonies' (Sydney Morning Herald 21.10.2002), these newly minted 'traditions' reproduced the distinctive endosociality that has strongly characterised Australian national identity since Federation in $1901 .^{5}$ By paddling off-shore to conduct their ceremonies, the surfers also enacted some of the separations between the nation and the state which Kapferer (1988) identified as essential to the individuating elements of the informal Anzac Day activities performed by war veterans after the official ceremonies 
conducted under the auspices of the state at war memorials. Expressions of insubordination and a popular flouting of laws against gambling, drunkenness and unruly public behaviour receive the implicit sanction of the state, which turns an official blindeye on them in honour of the veterans' sacrifices in service of the nation. These activities take place within Returned Services Leagues Clubs and other semi-official spaces, which become temporarily reanimated by the illicit activities of the clubs' patrons. The surfers' mourning ceremonies, like the mass Anzac rituals performed in recent years by young Anglo-Australian travellers on the beach at Gallipoli, receive some informal support from the state.

\section{Lebanese-Australian endosociality}

Bourdieu's description of men mobilising their collective sense of honour did not, of course, refer to Anglo-Aussie surfies but to the ideologies and practices of clan solidarity in the Kybele Arab households of Algeria where he conducted his major fieldwork. He was particularly interested in the effects of Arab patrilateral parallel cousin marriage (i.e. a man should marry his father's brother's daughter). These marriage prescriptions were seen to generate images of women in which a sharp differentiation was drawn between the qualities of those belonging to the patriclan who, being descendants of a centripetal family of brothers, are seen as 'the most masculine of women, cultivated, straightened' and are opposed to those from outside the patri-'house' who are paradigmatically represented as 'twisted, maleficent, impure' (Bourdieu 1977: 43). These 'outsider women' are perceived as being the 'source from which impurity and dishonour threaten to enter the lineage' (Bourdieu 1977: 43) because marrying outside the 'house' always implies a concomitant dilution of the 'blood' and material resources of the patriclan. It is interesting to compare in these terms the collective wounded pride of the Anglo-Aussie surfies with the collective identities proclaimed by some young Lebanese men, one of whom is cited by Poynting (2002: 158) to the effect: 'If you insult one of us, then you insult our brothers, and if you insult our brother, you insult our father, our mother, and put shame on the whole family'.

Here the relationship between brothers is the conduit to all other relationships; father, mother, and the rest of the family (in that order). The fraternal relationship is potentially the critical (and most vulnerable) of all relationships in the ideal Arab household because whom one's brother marries is seen to determine the fortunes of the rest of the family. Taking one of his father's brother's daughters as a wife maintains clan solidarity in a way that no other partner will but this situation also pits brothers and patrilateral male cousins against each other as rivals for the same pool of potential wives and as regulators of each other's marriage choices. According to the director of the Arab Council of Australia, an Arabic proverb runs thus: 'Me and my brother against my cousin, me and my cousin against the world' (Kattan 2006). The relationship between sons-in-law and fathers-inlaw remains dependent on the relationship between brothers in the first ascending generation, i.e. one's father and his brother. ${ }^{6}$

Statistics recently provided by demographers Bob Birrell and Edward Healy (2002) suggest that many Arab families have maintained these prescriptive marriage rules in Australia, even in the face of the radically altered conditions in which their children now encounter the other sex. ${ }^{7}$ At the most general level, inter-community endogamy rates are 75 per cent for women and 61 per cent for men who are accorded greater latitude in marrying out, partly because there is a general expectation that 'outsider' wives will either convert to Islam or assent to their children being brought up within the Islamic faith and within their husband's cultural community. Bourdieu suggested that the main 
thrust of the endogamous marriage ideal is to keep a women within the ambit of her father's family and/or community so that 'outsider' husbands do not produce a set of interests that conflict with those of their birth families. Birrell and Healy (2002) argued that the currently increasing incidence of in-marrying has impeded assimilation of Lebanese immigrants into the wider Australian community. ${ }^{8}$ Given the strong predilection for community endogamy in both the Muslim and Christian Lebanese communities, Anglo-Australian women are likely to represent the ultimate 'outsider' woman, constituting a potential threat to familial and community solidarity. The much higher rate of community exogamy of Lebanese-Australian men (39 per cent) compared to their sisters ( 25 per cent) suggests that 'outsider women' are also an object of desire for young men from these immigrant communities.

The Anglo-Australians who perceive these young immigrant men as going to the beach to bask in a sexualised ambience denied to them in their home suburbs are probably correct given that the culture of eroticism is at the heart of the beach experience for most young Australian adults. Andrew Lattas (2007) and Judy Lattas (2007) found that the racial tension at Cronulla is interpreted by some Anglo-Australians in terms of their distinct notions of 'etiquette' on the beach, particularly in regard to the ability to cognise and abide by such implicit rules of acceptable beach behaviour as when to avert one's gaze when challenged by an angry glare from a woman, when not to wear too much clothing, or how loudly and openly to make suggestive comments. There is an AngloAustralian ambivalence about whether Lebanese-Australian youths are just too different culturally to 'get' these rules or whether they are defiantly flouting them. That young Lebanese-Australians are perceived as behaving in a 'backward' manner, more like the Anglo-Australian adolescents who might make lewd comments to older girls, fatalistically emboldened by the knowledge that their chances to 'hook up' with them are negligible, suggests an Anglo recognition of their shared erotic goals but differentiated in terms of their own ethnic group's greater emotional intelligence.

\section{Islamophobia and incestophobia}

A splitting between bonds of affection (which involves some form of identification with another) and bonds of sexual desire (which usually implies a pleasurable and/or painful awareness of difference) permeates most human relationships. The incest taboo is fundamental to such splitting and it has been convincingly argued that the incest passions' and the taboo against it are critically constitutive of gendered identities (see Mimica 1991a and 1991b; Wagner 2001). The separations that the incest taboo institutes between siblings and between parents and children can be seen as producing sexual desire in all its permutations because psychophysical separation acts to maintain the fantasy of a deflected reunification which, in turn, produces a differentiating sexual desire. Anglo-Australian ambivalence about sexuality in the Arab family appears to arise, at least in part, from a perception that patrilateral cousin marriage is 'too close', invoking the commingled desire and abreactive horror associated with the incest fantasy. Radio and print media 'shock jocks' made a good deal of this theme of 'in-breeding' in their commentaries before and after the riot. ${ }^{9}$

There is some irony here given the fact that in the West the most celebrated patrilateral cousin marriage is that between the parents of Jesus Christ, the founder of the religion that fundamentally informs Western legal and moral systems. According to the Bible, Mary and Joseph were related in exactly this way. ${ }^{10}$ Ernest Jones (1923: 415-430) has shown how in this fundamental Christian myth Joseph's and Mary's sexual roles in the paternity of Christ are denied so that the fertilising role of Joseph's semen is ascribed 
instead to a spiritual agency, the Holy Ghost. This androgynous agent sublimates and transmits the Father's fertilising potency by splitting off the divine aspects of the Mother from her corporeality, producing an obviation of the Son's incestuous fantasy and culminating in the Son being ultimately reunited in the Holy Trinity of Father, Son and Holy Ghost (as recreated maternal-imago). This core origin myth or 'Divine Mystery' of Christian theology is thus thoroughly saturated with incestuous longings and defences, just like its Mithraic and Greek mythic predecessors. The moral precepts of Christianity are now regularly contrasted against those of Islam with which it shares so much epistemological common-ground, including the image of the sexually pure Virgin Mary. This can be understood as an attempt to derive moral authority from a renunciation of the incestuous fantasies that permeate both of these religious traditions. Anglo-Australian anxieties about the incestuous nature of Arab first-cousin marriage are but one particular manifestation of these fantasies.

The Anglo-Australian derision of the alleged psychophysi-

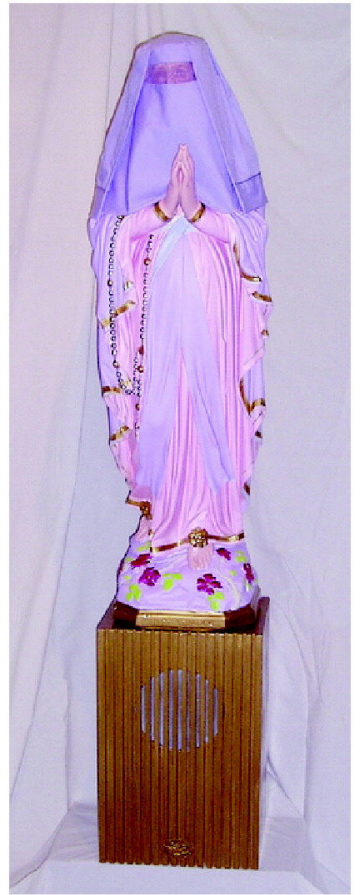

Figure 1. The Fourth Secret of Fatima. Sculpture by Luke

Sullivan. Reproduced by kind permission of the artist. 2007 ical 'backwardness' of Lebanese-Australian youth, seen to be a product of their sexually repressed upbringing, resonates with a more general Anglo-Australian perception of rural Lebanese immigrants as primitive 'country bumpkins'. This primitivist imagery is permeated with a sense that the incest taboo has failed in its cultural work in these social milieus so that its members must remain fixated on infantile object choices. This fixation in time is seen to make Lebanese youth clumsy and lacking panache in their overtures to women. Immigrant youth are perceived as being infantile in their inability to differentiate themselves adequately and this is held to account for their marriages to their cousins (who would be quasi-sisters in modern Anglo-Australian kin terms) as well as for an animal-like 'pack mentality'. Despite the various treatments of images of the invaded 'national body' in the now copious literature on Islampohobia (e.g. Mackey 1999), the effects of the incest fantasy/revulsion seem to have gone largely unremarked to date, though, as I have indicated above, this has certainly not been omitted from popular expressions of Islamophobia.

As with their Anglo-Australian counterparts, it would not be surprising if young Lebanese-Australian men's ambivalence about 'Skip' women were inflected with an anxiety arising from the incest taboo's injunction that they must be sexually attracted to someone not 'too close' in the family but also where marital (it may not be sexual) choices are restricted to patrilateral cousins. There is an expectation in all human social milieus that sexuality and familial affection should become split off from each other in order to propel men and women to acceptable marriage choices in which sexuality must not be altogether negated. Indeed, marriage to a parallel cousin must be seen not just as a functional means for solidifying the patriclan or 'house' but of creating the emotional distance which induces desire so that cousin-marriage is best understood as a means of culturally transforming a sister into a wife. While sexual encounters with 'outsider' girls may fulfill the same fantasy, they also have a potential to invoke breaks with one's own family and to produce violently conflicted attitudes towards outsider objects of desire. 
Does all this suggest, as some pundits have contended (Wilshire 2005; Windschuttle 2005), that it is the incommensurability between the cultural patrimony of young Lebanese Australians and Anglo-Australians' sexual and familial mores that is at the root of the Cronulla violence? This anxiety-laden conclusion is inflected with the very 'incest passions' that are declaimed in these commentators' calls for a cessation of current immigration and multicultural policies, which supposedly support the coexistence of radically different cultural worlds within a unified Australian national body. The neoconservative newspaper columnist, Greg Sheridan, was one of those whose incest passions/horrors rose to the surface in the wake of the first Gulf War when he contended that it was imperative that the West 'intervene so forcefully that it breaks Arab attachment to Arab culture' (Sheridan 1990: 28), thus clearly invoking the image of the separating Father breaking infantile maternal attachments. The very notion of Australia as 'one nation' with a unified, self-enclosing set of values can be seen as an instantiation of that desire for autochthony which Levi-Strauss has shown to be deeply implicated in the central problematic of incest - are we 'born from one or born from two...born from one or born from different?' (1963: 216).

The notion that there are two radically different cultural worlds in conflict in Australian cities has been questioned by Katie Englert (2005) who suggested that amidst all the 'dog-whistle politics and journalism' and the Anglo 'moral panics' about immigrant Lebanese-Australian youth gangs, there are at least as many similarities as differences between the sexual mores and identities of young Anglo and Lebanese Australian men, the two groups in most open conflict for the attention and/or possession of the young women at Cronulla. In the course of her archive-based master's research, Englert found evidence, in both the Anglo- and Lebanese-Australian communities, of anxiety about the nature of authority within the family and the neighbourhood. She pointed to signs of a strong nostalgia in both of these social milieus for a family structure exercising greater control over the sexuality of their young.

Englert pointed to the anxiety evoked in the press reportage of the racially targeted sexual assaults on young women by some young Lebanese- and Pakistani-Australian men from Sydney's south-western suburbs in $2000 .{ }^{11}$ The rapists themselves made it quite clear that they consciously targeted 'Skips' (though what constitutes a Skip in this context, turns out to mean non-Lebanese women-Englert's reading of the trial and media transcripts revealed that one of their victims was of Aboriginal and another of Italian descent). The polarisation over race in these cases was produced around the victims vis à vis the perpetrators of the crimes.

During the trials of the rapists, the public's anxiety also came to focus on the alleged recklessness of the young, female victims in joining the Lebanese-Australian youths in impromptu social encounters (smoking marijuana with them, riding in their cars), which were widely perceived as having set the scene for the subsequent rapes. During the trial, the newspapers made a great deal of the rapists' own statements that Anglo-Australian girls were 'sluts'. It was clear from these statements that the victims' distance from the rapists own kinship world made them both more vulnerable and more desirable and exacerbated the violent attack. This racial separation seemed to work towards obliterating any tendency to identify with their victims (even indirectly as another man's sister or daughter, something the rapists may have been unable to disregard in relation to a Lebanese-Australian girl). 


\section{Team spirit}

At around the same time, reports emerged of the so-called 'gang-bangs' by professional football players at a tourist resort in Coffs Harbour, in coastal New South Wales. These reports raised the unsettling and, for many, shame-inducing, spectre of young women engaged in a foolhardy sexual adventurism, which 'ended in tears'. While these women were reported to be seeking prestigious sexual conquests ('star-fucking') and thus as engaging in a dangerously instrumental self-reification, what did not receive much discussion was the nature of the relationships played out between the male 'team-mates' who embarked together on these escapades. Here sex is attributed with a powerful efficacy in forging group identity rather than as something contained within a bounded individual or produced within an intersexual relation between two individuals.

Despite the ambiguities around notions of pleasure, crime and punishment in the press reports of these different cases, it is likely that some similar fantasies informed the responses to both the footballers' 'gang-bangs' and the Sydney pack-rapes. These kinds of psycho-sexual dynamics also appeared in the recent biography of the Australian cricketer, Shane Warne (Barry 2006), which revealed some of the workings of male bonding through group sexual adventures by Australian Test cricketers, whether these were played out in individual encounters that afterwards become the topic of conversation amongst team-mates, or in actual group sexual encounters. Barry reported on a culture of competitive sexual boasting amongst team players so that Warne, for example, is said to have forwarded erotic SMS-es received from admiring women to his team-mates. This kind of competitive bonding of team-mates through erotic adventures shared within a small group bound by a culture of secrecy ('what goes on tour stays on tour') was constituted in opposition to the team members' spouses who were perceived as a threat to male group identity and, by extension, to their sporting performance. Homoerotic bonds were cemented through the team members shared and competitive sexual experiences in which the object of desire resolutely remained heterosexual but in which the relationship between men was constituted through their relationships to women, or a woman. A female object of desire served to mediate and exteriorise male homoeroticism and masked the serial endogamy that sporting teams engender. The Anglo-Australian kinship ideal that married men should abandon (to some degree) their male cohorts is often in direct conflict with a culturally valorised devotion within a group of male mates, as Tom Ernst's (1990) analysis of this subject made clear.

Englert (2005) suggested that the public response to the pack-rapes and the 'gangbang' was informed by a wistful but ambivalent evocation of the disappearing ideal of the authoritarian family, something perceived as only persisting in 'backward' immigrant communities - such as rural Arab villages. Within the Lebanese immigrant community itself the patriarchal family is also experienced as being under threat from a highly sexualised and secularised economy. Poynting (2002) cites a number of examples from Lebanese community spokespersons regarding this general disquiet over the loss of traditional familial authority. Sheik El-Hilaly, the controversial Mufti of Australia (who in 2006 outraged sectors of public opinion by asserting that the provocative way in which secular women dressed made them as attractive to rapists as 'uncovered meat to a cat') complained that in Australia, 'the law doesn't give the power for families to control their kids'.

Within the Anglo-Australian population, a sexually repressive family model seems to be perceived, on the one hand, as a threat to modern Australian consumption values and, on the other, as an object of some envy for parents anxious about their children's sexual lives. Strong cultural constraints maintained against sexual pleasure may become 
incommensurate with a consumer ethic which has produced unprecedented levels of family debt in Australian households. This high level of debt speaks to an abandonment of the self-denying 'thrift is best' ethic which dominated 1950s and early $1960 \mathrm{~s}$ Australian spending habits (see also Jules Henry (1966) on a similar cultural shift geared towards boosting the post-World War II US economy). Alongside this apparent abandonment of consumer caution, frequent panics arise about the long-term effects, particularly on the young, of an ethic of consumer indulgence. Fears of the social effects of unbridled consumption manifests in part in a range of anxieties about young people's recreational sex and drug lives. While the particular historical forms of the family obviously shape the nature of consumption styles, the market that simultaneously makes and is tailored to these styles also shapes the familial matrix.

Young Anglo-Australian and Lebanese male ethnic and gender identities are coproduced in their battles for the sexual attention/possession of young women and the public spaces where they congregate. Young White males attempted to dismiss the immigrant youth, characterised by some Cronulla surfies as 'hairy-backed monkeys', as being no threat to their own ability to monopolise Anglo-Aussie women. By invoking that jungle imagery, surfies displayed anxiety about the imagined primordial sexual potency of dark strangers, deploying the same kind of imagery with which a previous generation of young Anglo-Australians caricatured the dangerously threatening allure of the 'Rockers', often the children of the Mediterranean immigrant influx of the postWorld War II era. It seems to have been hardly noticed that these images of young 'Wog' men's cultural world closely mirrored that of working-class Anglo-Australian men (e.g. intense sporting loyalties, automobile erotica, strong male friendship groups). The 'Wog comedy' television program Pizza shows how closely convergent these traditions are. Indeed, the once exclusively 'ethnic' hip-hop ethos has now been widely embraced by the youngest generation of Anglo-Aussie teenagers.

In a domestic context, the parental generation of the Anglo- and Lebanese-Australian populations are clearly anxious about the social and sexual lives of their children. These local identities and anxieties, partake, in turn, of the ideological and military battles being waged for moral and political-economic dominance at an international level. Some analyses of the Cronulla White riot, its preceding provocations and the subsequent retaliation attacks, have implicitly or explicitly suggested that all the participants are 'equally to blame', implying a notion of racial and class complementarity to which the proposed solution is a restoration of the status quo of civil society which betrays a fear of youth in general while failing to recognise the marked socio-economic disadvantage of Lebanese immigrant youth. ${ }^{12}$

\section{Conclusion}

In the affluent, and predominantly Anglo Sutherland Shire (also known as "the insular peninsula') neighbourhood and extended kinship ties have been pitted against a spatially and morally separated immigrant threat. This ethnic and class separation is activated principally by young men in relation to the young women whom they claim to defend as a group. The Cronulla surfers and their working-class counterparts, the 'Bra Boys' (surfers who emerged from the public housing estates of Maroubra), constitute 'brotherhoods', which have long been infamous for a strong 'locals only' ethic. ${ }^{13}$ The subtitle of the Bra Boys recent homemade documentary (Abberton 2007), 'Blood is Thicker than Water', and their motto, 'My Brother's Keeper', which many of this group have had tattooed onto their bodies, dramatically capture the group's mixture of nurturance and internal hierarchy. For at least two generations now, Cronulla surfers have 
defended their turf from outsiders hailing from the inland, working-class suburbs. Historically, this Outsider included other Anglo-Australians who arrived at Cronulla by train for surfing day trips from the western and south-western suburbs and came to be dubbed as 'Billy Bankstowns' in the 1970s (David Votz, pers. comm. 2007). During the Cronulla riot and its aftermath, Anglo-Australian surfies identified their sub-culture, often imagined as evasive of the power of the state, as partaking of the very essence of the Australian nation, even as they pitted themselves against the forces of the state (police, fire-service and ambulance personnel) and immigrant intruders. The result has been to create saturation policing of the suburb, ostensibly to deter future riots by young White men but in effect satisfying the older residents of the Shire's long-articulated desire for greater police control of the public spaces where young people have congregated.

The White rioters desire to retain their insularity mimics an increasingly insular and chauvinistic Australian national political culture that articulates with the family fantasy of a 'little brother/big brother' kin relationship with a much more powerful United States (which continues to maintain an ideology of domestic insularity belying its global interventions). This putative kinship relationship, while espousing ever greater insularity against so-called 'illegal immigrants' (asylum seekers), has enabled Australians to push the internal boundaries of what constitutes 'home' ever further afield into the Pacific and South-East Asia. This has been achieved through taking up the ultimately resented, but security-inducing, role of younger brother to the United States.

In this paper I have argued that the strong homosociality exhibited in a range of different contexts by young Australian men involves forms of separation productive of particular kinds of heterosexual identity, just as the separations of the incest taboo attempt to do. These separations can be observed amongst Anglo-Australian men in the barbecue area, in a sports team's 'gang-bang', and in their policing of the exclusivity of a neighbourhood beach. A parallel homosociality amongst young Lebanese-Australian men can be observed in strongly developed fraternal and cousin relationships, as a factor in a notorious series of violent gang rapes, and in the response to the White riot at Cronulla. Social separations and solidarities characterise the relationships between these young men, which bind them together in a joint project of 'protection' or possession of young women. The gender separation operates in conjunction with other forms of separation which relationally reproduce ethnic and class inequalities. The feuds between these young men play out the class and ethnic conflicts of the young men's parental and grandparental generations in the public arena, as John Clarke's (1975) classic analysis of the Skinhead social-worlds in the London Docklands also suggested. Members of the two senior generations have actively incited their young to defend their turf ${ }^{14}$ while disclaiming any culpability for the ensuing civil disorder.

These conflicts are informed in a substantial way by incestophobia and a concomitant anxiety about the splintering of fraternal bonds forged in relation to a common ancestor or common object of desire. This relationship between fraternal splitting and incestophobia invokes the conflict between older and younger siblings over their fantasised possession of a single object of desire. When one social entity presents itself as the genuinely loved object, this refutes claims to that same status made by an opposed social entity which is then declaimed as false, corrupted or failing to offer salvation or genuine reunification with the loved object. This dynamic is evident, for example, in the bifurcating relationship of Christianity and Islam in relation to their common paternal source, Judaism. The vicissitudes of a younger brother/older brother kinship dynamic and the impact of incestophobia also become evident in the Australian nation's imaginary relationship to the USA in regard to a common Mother England. A conflict of this nature has long been evident in the antagonism between surfies (imagined as younger brother) 
versus the much longer-established clubbies (imagined as older brother). The ideal-type relationship between Lebanese brothers and then between these groups of brothers vis à vis their cousins seems to evoke an ambivalence that is readily deflected onto outsider women imagined as the source of conflict between men who think of themselves as otherwise deeply committed to acting in each other's interests. The exchange of insults preceding, and subsequent to, the Cronulla riot provided a set of circumstances in which ambivalences within, and between, a range of fraternal groups raised anxieties regarding incestophobia and homoerotic bonding to a pitch that was able to be expunged only through the physical confrontations of 11 and 12 December, 2005.

\section{Acknowledgements}

This anthropological analysis draws extensively on the materials analysed by Katie Englert (2005) in her MA thesis and on my conversations with her. I also draw on my own experiences in the Anglo-Australian 'surfie' sub-culture and of the attitudes towards 'Westie' outsiders. An earlier version of this paper was presented at the Australian Anthropological Society Annual Conference in Cairns in September 2006, where the comments from the audience were most helpful. I also thank Andrew and Judy Lattas, Diana McCarthy, Rohan Bastin, Simon Corey, Alan Rumsey and the three anonymous reviewers for their helpful comments. I am especially grateful to the Australian artist Luke Sullivan for granting me permission to use his image titled 'The Fourth Secret of Fatima', reproduced her in Figure 1, p.342. All interpretations of the material remain, of course, my own responsibility.

\section{Notes}

1. In the week following the assaults on the life-savers, shock-jocks Steve Price of radio station 2UE and Alan Jones of $2 \mathrm{~GB}$, called for 'a community show of force' at Cronulla and the Murdoch-owned Daily Telegraph supported a campaign to defend the 'Australian Way' on the beach.

2. As Katie Englert's (2005) MA thesis showed, one of the most powerful tropes in popular and media depictions of young Lebanese-Australians is their 'groupiness', their strong familial bonds, and their ethnic solidarity.

3. Various radio hosts and politicians among the Anglo-Australian parental and grandparental generation explicitly or implicitly endorsed the cry for a show of force against Lebanese youth at Cronulla. Later, when the broadcasting regulatory body's Australian Communications and Media Authority (ACMA) ruled that shock-jock Alan Jones had encouraged violence against Lebanese people in his broadcasts, Prime Minister John Howard acclaimed Jones as an 'outstanding broadcaster' who was brave enough to say on air what many nameless people (presumably including the Prime Minister) think. Opposition Leader, Kevin Rudd, also endorsed Jones' public standing (The Age 11.04.2007).

4. One indication of this solemnising impulse was evident in Bali in October 2003. The Sydney Morning Herald reported that, "Australians want to buy Bali's Sari Club, bombed in last October's terrorist attack, as a "sacred site". The fate of the levelled club site took a new twist yesterday when a group of Australians affected by the bombings announced a bold plan to buy it' (Sydney Morning Herald 13.10.2003).

5. In 2004, aspiring Prime Minister, Mark Latham, announced at the Coogee memorial ceremonies: 'When things get tough we stick together as a people, when our mates are in trouble, we are always there with a helping hand' (Sydney Morning Herald 13.10.2004).

6. Bourdieu's now famous emphasis upon how individual agents manipulate and evade the structural relationships of 'official kinship' does not nullify the constraining effects of those structures but shows how ideologies for action are reproduced in the face of innovation and evasion. 
7. A much cited study at Auburn Hospital in Sydney's southwest, for example, found almost twenty per cent of pregnant women admitted to the maternity ward in one year were married to their first or second cousins. The Sun Herald reported in more detail on 28.05.2006, in a piece entitled 'The Family Ties that Bind':

'What was interesting,' de Costa wrote at the time, 'was that the proportion of pregnant women who were consanguineously married had risen from 11 per cent in the 1980 s to 19.6 per cent in $1999 \ldots$ In other words ... consanguineous marriage is continuing to be commonly practised by the next generation'... Australia is by no means unique in this regard. Around 55 per cent of Pakistanis in the United Kingdom are reported to be married to their first cousins.

8. The rates of Anglo-Australian community in-marriage in both ethnic and class terms would make an interesting comparison.

9. The following comments about Lebanese-Australians were made on Sydney Radio $2 \mathrm{~GB}$ by an announcer (Wilshire 2005):

Brian Wilshire: We Australians do not have to apologise for anything. My anger is reserved for the politicians and bureaucrats who conspired to bring in people who were guaranteed to be incompatible and have demonstrated that in every country into which they have moved.

Francis: Absolutely. Look, I couldn't agree with you more.

Brian Wilshire: Many of them have parents who were first cousins, whose parents were first cousins, because of the culture-it's not a religious thing, it doesn't say this in the Koran - but it's a cultural thing for some part of the world to have parents who are very closely related. The result of this is inbreeding, the result of which is uneducationable [sic] people, and very low IQ.

10. 'Mary and Joseph were therefore first cousins, and both of the house of David. Jacob, the elder, having died without male issue, transmitted his rights and privileges to the male issue of his brother Heli, Joseph, who according to genealogical usage was his descendant' (Tierney 1910).

11. 'In the days before the Cronulla riots on 11 December that year, Jones referred to Lebanese as "grubs", "thugs" and "cowards" who would retreat to their lair if confronted by motorbike gangs. He also said: "We don't have Anglo-Saxon kids out there raping women in western Sydney".' The Age 11.04.2007

12. Healy and Birrell (2003: 65) provide the following snapshot of the socio-economic disadvantage of Lebanese migrant youth:

There are now two Sydneys - one increasingly dominated by low to moderateincome non-English-speaking migrant communities in the West and South West and the other comprised of established inner affluent areas and predominantly English-speaking 'aspirational' areas on the metropolitan periphery. In the high migrant, low to moderate-income areas in the West and South Western suburbs, Australian-born residents are moving out at greater rates than overseas-born residents. In turn, low and moderate-income overseas arrivals continue to settle disproportionately in these locations.

13. Sydney University academic, Clifton Evers (2007), has tried to convince us that most surfies, unlike the Bra Boys, are just good citizens who like nothing better than to help the unfortunate people of the Third World in their spare time - 'just blokes who go to work like everyone else but love a surf as well ... who have moved beyond the counter-culture ethos'. Although that may well be for middle-class academics like Evers and myself, many of the hundreds of thousands of school-age teenagers who make up the largest part of the Australian surfing world do not yet have jobs, houses, or other property and the social prestige that goes with it. When they are not surfing there is considerable personal investment in the same 'bongpulling' and 'grog'-fuelled partying and fighting that generally characterises the life of young, 
and not so young, working-class Australian men and which the documentary film Bra Boys (Abberton 2007) showed so vividly.

14. The ACMA found that Alan Jones' broadcasts of December 2005 had incited racial hatred.

\section{References}

Abberton, S. 2007. Bra Boys. Documentary, 90 minutes. Directed and produced by S. Abberton. Braderhood Productions. Distributed by Hopscotch.

Abraham, Y. 2005. On the beach: why the recent riots in Australia should surprise noone. Boston Globe, 25 December. Available at: URL http://www.boston.com/news/globe/ideas/articles/2005/ $12 / 25 /$ on_the_beach?mode $=\mathrm{PF}$

Barry, P. 2006. Spun Out: The Shane Warne Story. Sydney, NSW: Bantam Press.

Birrell, B. and E. Healy 2002. Out-marriage and the survival of ethnic communities in Australia. People and Place 8(3): 37-46.

Bourdieu, P. 1977. Outline of a Theory of Practice. Translated by R. Nice. Cambridge; New York, NY: Cambridge University Press.

Clarke, J. 1975. Skinheads and the Study of Youth Culture. Birmingham: University of Birmingham.

Englert, K. 2005. Pictures Worth Thousands of Words: Youth, Ethnicity and Photography. MA Thesis. Canberra, ACT, Australian National University.

Ernst, T. 1990. Mates, wives and children: an exploration of concepts of relatedness in Australian culture. In J. Marcus (ed.) Writing Australian Culture: Text, Society and National Identity. Social Analysis Special Issue 27: 110-118.

Evans-Pritchard, E. 1940. The Nuer: A Description of the Modes of Livelihood and Political Institutions of a Nilotic people. Oxford: Oxford University Press.

Evers, C. 2007. False prophets of surfing bastardise our beaches (a review of Bra Boys). Sydney Morning Herald, 13 March.

Hage, G. 1998. White Nation: Fantasies of White Supremacy in a Multicultural Society. Sydney, NSW: Pluto Press.

Hage, G. 2003, Against Paranoid Nationalism: Searching for Hope in a Shrinking Society. Sydney, NSW: Pluto Press; London: Merlin Press.

Healy, E. and B. Birrell. 2003. Metropolis divided: the political dynamic of spatial inequality and migrant settlement in Sydney. People and Place 11 (2): 65-85.

Henry, J. 1966. Culture Against Man. London: Social Science Paperbacks in association with Tavistock Publications.

Jones, E. 1923. Essays in Applied Psychoanalysis. London and Vienna: International Psychoanalytical Press.

Kapferer, B. 1988. Legends of People, Myths of State: Violence, Intolerance, and Political Culture in Sri Lanka and Australia. Washington, DC: Smithsonian Institution Press.

Lattas, A. 2007. 'They always seem to be angry': the Cronulla riot and the civilising pleasures of the sun. The Australian Journal of Anthropology 18(3): 300-319.

Lattas, J. 2007. Cruising: 'moral panic' and the Cronulla riots. The Australian Journal of Anthropology 18(3): 320-335.

Kattan, R. 2006. The Australian, January 28.

Levi-Strauss, C. 1963. Structural Anthropology. New York, NY. Basic Books.

Mackey, E. 1999. Constructing an endangered nation: risk, race and rationality in Australia's Native Title debate. In D. Lupton (ed.), Risk and Sociocultural Theory: New Directions And Perspectives, pp.108-130. Cambridge: Cambridge University Press.

MacRae, G. 2006. Fear and loathing in our own holiday paradise: the strange tale of Schapelle Corby (et al.). In Noszlopy, L. (ed.) The Schapelle Corby show: drugs, media and society, pp.79-85. Soapbox Forum. The Australian Journal of Anthropology 17(1): 70-85.

Mimica, J. 1991a and 1991b. The incest passions. An outline of the logic of Iqwaye social organisation. Oceania 62 (1): 34-56; (2): 81-113. 
Poynting, S 2002. Street Arabs and mug liars: racism, class relations and moral panic about Lebanese-Australian youth. In G. Hage (ed.) Arab-Australians Today: Citizenship and Belonging, pp.145-160. Melbourne, VIC: Melbourne University Press.

Sheridan, G. 1990. When power is the measure of honour and honour the measure of tragedy. The Australian, 1 December, p. 28.

Tierney, T. 1910. The Catholic Encyclopedia, Volume VII. Robert Appleton Company. Online Edition Copyright (C) 2003 by K. Knight. Available at: URL http://www.newadvent.org/cathen/ 07204b.htm (accessed 20.04.2006).

Wagner, R. 2001. An Anthropology of the Subject: Holographic Worldview and its Meaning and Significance for the World of Anthropology. Berkeley, CA: University of California Press.

Wilshire, B. 2005. Comments made on radio station 2GB, 15 December, reported by the Australian Broadcasting Commission's Media Watch. URL http://www.abc.netau/mediawatch/transcripts/ s1574242.htm (accessed 20.02.2006).

Windschuttle, K. 2005. It's not a race war, it's a clash of cultures. The Australian, 16 December. 